questionnaire survey in Japan. Brain Dev Nov 2008;30:629-635). (Respond: T Tanabe. Email: tanabemapa@pop01.odn.ne.jp).

COMMENT. The use of bromides for treatment of SMEI and their significantly higher efficacy than that of valproic acid and zonisamide are interesting and surprising observations. Bromides were first introduced for the treatment of epilepsy in 1853 (Locock C. Lancet May 23, 1857;527). After phenobarbital became available in 1912 and phenytoin in 1937, the use of bromides was largely discontinued. The administration of bromides is not as simple as that of newer anticonvulsant drugs. Its effectiveness depends on a lowered intake of sodium chloride in the diet. The onset of action is delayed for 2 to 3 weeks, and high blood levels are maintained for 1 to 2 weeks after bromides are discontinued. Unlike other anticonvulsants, an abrupt withdrawal of bromides is unlikely to precipitate status epilepticus.

Bromides are usually administered in liquid or tablet forms of sodium bromide or as triple bromide elixir, containing $400 \mathrm{mg}$ each of sodium, potassium and ammonium bromide per 5ml. (Livingston S et al. Amer J Dis Child 1953;86:717-720)(Goodman LS, Gilman A. The Pharmacological Basis of Therapeutics. New York. Macmillan, 1955;156-163). Suggested starting and maintenance doses of bromides are as follows: For children under 3 years old, $160 \mathrm{mg} 2 \mathrm{x}$ daily (maximum $320 \mathrm{mg} 3 \mathrm{x}$ daily); 3 to 6 years old, $320 \mathrm{mg} 2 \mathrm{x}$ daily (maximum $640 \mathrm{mg} 3 \mathrm{x}$ daily). (Livingston S. Comprehensive Management of Epilepsy in Infancy, Childhood and Adolescence. Springfield, IL. Charles C Thomas, 1972;198, 268274). A satisfactory blood level of bromides is generally 20 to $25 \mathrm{mEq} / \mathrm{L}$ (160 to $200 \mathrm{mg} \%$ ). Drowsiness and cutaneous reactions are the most troublesome side effects. Administration of extra sodium chloride and fluids usually alleviates drowsiness. Acneiform rashes are a frequent occurrence in adolescents and adults, but are uncommon in infants and young children. Granulomatous lesions (bromoderma) will occur occasionally, taking months to disappear after bromide withdrawal.

Epileptic syndromes with high rates of status epilepticus, in addition to SMEI, include Panayiotopoulos syndrome and symptomatic occipital lobe epilepsy secondary to neonatal hypoglycemia (Okanishi T et al. Brain Dev Nov 2008;30:624-628).

\title{
RISK OF EPILEPSY IN OFFSPRING EXPOSED TO PREECLAMPSIA OR ECLAMPSIA
}

Researchers at the University of Aarhus, Denmark, and at centers in China and US, conducted a population-based study of singletons born in Denmark (1978-2004) with information on preeclampsia and epilepsy obtained from the Danish National Hospital Register. They identified $2.9 \%$ of children exposed to preeclampsia, and $0.04 \%$ to eclampsia during prenatal life. The incidence of epilepsy at 27 -year follow-up was increased following exposure to either preeclampsia or eclampsia in children born after 37 weeks of gestation. Children born preterm showed no association between preeclampsia and epilepsy. In contrast, the incidence rate ratios were 1.29 for children born at term and 5.03 for children born postterm. (Wu CS, Sun Y, Vestergaard M, et al. Preeclampsia and risk for epilepsy in offspring. Pediatrics Nov 2008;122:1072-1078). (Respond: Chun Sen Wu MD, E-mail: cw@soci.au.dk). 